\title{
Layered Double Hydroxide Clusters as Precursors of Novel Multifunctional Layers: A Bottom-Up Approach
}

\author{
Cristina S. Neves ${ }^{1}$, Alexandre C. Bastos ${ }^{1}$, Andrei N. Salak ${ }^{1}{ }^{\circledR}$, Maksim Starykevich ${ }^{1}$, \\ Daisy Rocha ${ }^{2}$, Mikhail L. Zheludkevich ${ }^{3}$, Angela Cunha ${ }^{2}{ }^{\circledR}$, Adelaide Almeida ${ }^{2}{ }^{\circledR}$, \\ João Tedim ${ }^{1, *(1)}$ and Mário G.S. Ferreira ${ }^{1}$ (1) \\ 1 Department of Materials Engineering and Ceramics, CICECO, University of Aveiro, 3810-193 Aveiro, \\ Portugal; cristina.neves@ua.pt (C.S.N.); acbastos@ua.pt (A.C.B.); salak@ua.pt (A.N.S.); \\ mstarykevich@ua.pt (M.S.); mgferreira@ua.pt (M.G.S.F.) \\ 2 Department of Biology and CESAM, University of Aveiro, 3810-193 Aveiro, Portugal; \\ deisyrocha@ua.pt (D.R.); acunha@ua.pt (A.C.); aalmeida@ua.pt (A.A.) \\ 3 MagIC - Magnesium Innovation Centre, Helmholtz-Zentrum Geesthacht, Max-Planck Straße 1, \\ 21502 Geesthacht, Germany; Mikhail.Zheludkevich@hzg.de \\ * Correspondence: joao.tedim@ua.pt
}

Received: 26 April 2019; Accepted: 16 May 2019; Published: 21 May 2019

\begin{abstract}
The specific microstructure of aluminum alloys is herein explored to grow spatially-resolved layered double hydroxide (SR-LDH) clusters on their surface. Upon chemical modification of LDHs via intercalation, adsorption and grafting with different functional molecules, novel surface-engineered surfaces were obtained. Crystal structure and phase composition were analyzed by X-ray diffraction (XRD) and surface morphology was observed by scanning electron microscopy (SEM). X-ray photoelectron spectroscopy (XPS) and glow discharge optical emission spectrometry (GDOES) were used to correlate structural changes upon ion-exchange and interfacial modifications with chemical composition and surface profiles of the SR-LDH films, respectively. The protection conferred by these films against localized corrosion was investigated at microscale using the scanning vibrating electrode technique (SVET). $\mathrm{LDH}-\mathrm{NO}_{3}$ phase was obtained by direct growth onto AA2024 surface, as evidenced by (003) and (006) XRD diffraction reflections. After anion exchange of nitrate with 2-mercaptobenzothiazole (MBT) there was a decrease in the SR-LDH thickness inferred from GDOES profiles. The subsequent surface functionalization with HTMS was confirmed by the presence of Si signal in XPS and GDOES analyses, leading to an increase in the water contact angle (c.a $144^{\circ} \pm 3^{\circ}$ ). SVET measurements of the SR-LDH films revealed exceptional corrosion resistance, whereas the bioluminescent bacteria assay proved the anti-microbial character of the obtained films. Overall the results obtained show an effective corrosion protection of the SR-LDHs when compared to the bare substrate and the potential of these films for biofouling applications as new $\mathrm{Cr}$-free pre-treatments.
\end{abstract}

Keywords: layered double hydroxides (LDH); conversion films; corrosion protection; surface treatment

\section{Introduction}

Nowadays, there is a growing interest towards the development of coatings and smart interfaces enclosing multiple functionalities within the same matrix, aiming at improved performance, high durability, lower toxicity and cost-effectiveness [1].

Aluminum is rarely found in nature in its metallic form as it is thermodynamically unstable, and must be processed from ores such as bauxite, using high energetic processes in order to be reduced back to the metallic form [2]. However, its high tendency to oxidize in the presence of oxygen is limited by the formation of a well-adherent, passivating oxide layer which keeps the underlying metal 
protected. For most high-performing applications, though, $\mathrm{Al}$ has to be alloyed with other elements in order to improve the mechanical properties. The presence of intermetallic phases rich in other elements (e.g., $\mathrm{Cu}$ or $\mathrm{Fe}$ ) makes $\mathrm{Al}$ alloys more susceptible to localized corrosion attack with respect to pure $\mathrm{Al}$, thereby requiring additional protective measures.

With the increase of environmental awareness in most recent decades came the prohibition of effective (yet toxic) approaches to solve some of these issues, namely the use of chromate conversion coatings [3,4], creating a gap between the need for performance under extreme conditions and the existence of more environmentally-friendly advanced materials. A recently proposed strategy relies on the formation of conversion films using the substrate as source of reactants to make a well adhered layer, capable of acting as the first protection level against ingress of $\mathrm{H}_{2} \mathrm{O}, \mathrm{O}_{2}$ and oxide disrupting species such as chlorides. Several studies have showed the ability to grow layered double hydroxide films (LDHs) on the surface of aluminum alloys [3,5-7]. LDHs are plate-like materials commonly expressed as $\left[\mathrm{M}^{2+}{ }_{1-\mathrm{x}} \mathrm{N}^{3+}{ }_{\mathrm{x}}\left(\mathrm{HO}^{-}\right)_{2}\right]^{\mathrm{x}+}\left[\left(\mathrm{X}^{\mathrm{n}-}\right)_{\mathrm{x} / \mathrm{n}} \cdot y \mathrm{H}_{2} \mathrm{O}\right]^{\mathrm{x}-}$, where $\mathrm{M}^{2+}$ and $\mathrm{M}^{3+}$ are divalent and trivalent cations respectively, that occupy octahedral positions in the hydroxide layers and $\mathrm{X}^{\mathrm{n}-}$ is any interchangeable anion positioned in the gallery between the layers [8]. The first works on the growth of LDHs available in the literature aimed at obtaining a smooth uniform layer of LDHs, imparting only one type of modification to protect the substrate, typically based on "barrier" [9] or superhydrophobicity effects [10-13]. A more recent trend relies on the use of LDHs as sealing of anodized layers [14-16] to impart additional active corrosion protection.

In the present work we re-visit a facile method for the growth of LDHs directly on the surface of aluminum alloy 2024 (AA2024), to provide active corrosion protection via controlled release of corrosion inhibitors $[6,7,17]$. This methodology explores the weakness of the native aluminum oxide layer, promoting differentiated growth of LDH clusters due to the faster dissolution of aluminum in weak sites of the aluminum oxide layer (hence, the spatially-resolved LDH designation use hereafter, SR-LDH). Furthermore, the spatial growth of LDHs can be controlled by changing the surface pre-treatment and reactant concentration, as already shown previously $[6,7,17]$.

In this work, we report a simple manner to build a thin, multifunctional layer with anticorrosion and biocidal characteristics, from a simple surface pre-treatment of aluminum alloys as a potential replacement of $\mathrm{Cr}$ (VI)-based conversion coatings. The innovative concept explored is based on differentiation of properties at metal-LDH interface/LDH layer (bulk)/LDH-solution interface, building each of them with a set of characteristics in a bottom-up manner. In this way, we can choose the "bricks" (i.e., the properties) to impart or combine within the same protective layer. These layers have been modified with 2-mercaptobenzothiazole (MBT) and surface-modified with a hydrophobic silane (hexadecyltrimetoxisilane, HTMS) for the first time, in an attempt of obtaining a multifunctional surface with different levels of protection, namely: (i) direct growth of LDHs to provide good coating adhesion, (ii) active corrosion protection by release of MBT and (iii) water/ions displacement from interface via hydrophobic effect imparted by HTMS. Furthermore, the interplay of low surface energy and MBT-imparted biological activity can have other potential advantages such as anti-microbial action, herein assessed using a bioluminescent bacteria assay.

\section{Materials and Methods}

\subsection{Materials}

All the chemicals were obtained from Sigma-Aldrich (Sintra, Portugal), with $>98 \%$ of ground substance, and used as received.

\subsection{Preparation of Aluminum Alloys}

AA2024-T3 plates (Service Centres Aero France (Nantes, France); composition: Cr max. 0.1\%; Cu 3.8\%-4.9\%; Fe max. 0.5\%; Mg 1.2\%-1.8\%; Mn 0.3\%-0.9\%; Si max. 0.5\%; Ti max. 0.15\%; Zn max. $0.25 \%$ and $\mathrm{Al}$ balance) were rinsed successively with deionized $\mathrm{H}_{2} \mathrm{O}$, followed by acetone for removal of 
particulates and degreasing. Then, AA2024 plates were surface treated using an industrial/commercial procedure. Briefly, the plates were immersed twice in a $2.5 \%$ Gardacid solution for $45 \mathrm{~s}$ followed by acid etching trough immersion of the plates in Turco Liquid Smutgo NC for $7 \mathrm{~min}$. Each step was followed by washing with deionized $\mathrm{H}_{2} \mathrm{O}$. Finally, the AA2024 plates were dried in air.

\subsection{Synthesis of LDH Layer}

The nanostructured LDH layers synthesized in this work are ZnAl LDH. The cleaned AA2024 plates were immersed in a $5 \mathrm{mM} \mathrm{Zn}\left(\mathrm{NO}_{3}\right)_{2}$ solution with a $\mathrm{pH}$ in the neutral range for $4 \mathrm{~h}$ under hydrothermal treatment $\left(\mathrm{T} \approx 100^{\circ} \mathrm{C}\right)$. Subsequently, the plates were washed with ultrapure $\mathrm{H}_{2} \mathrm{O}$, ethanol, and dried in air (SR-LDH-NO ${ }_{3}$ was obtained). SR-LDH-MBT was obtained by immersion of SR-LDH-NO ${ }_{3}$ coated plates in a $0.1 \mathrm{M}$ sodium mercapthobenzothiazolate solution-NaMBT (prepared in advance from the equimolar reaction of 2-mercaptobenzothiazole- $\mathrm{MBT}$ - with sodium hydroxide- $\mathrm{NaOH}$ ) for a few hours under hydrothermal treatment $\left(\mathrm{T} \approx 50^{\circ} \mathrm{C}\right)$. For surface functionalization SR-LDH-MBT coated plates were immersed in acetonitrile, containing the desired amount of hexadecyltrimetoxisilane-HTMS, for a few hours under hydrothermal treatment $\left(\mathrm{T} \approx 80^{\circ} \mathrm{C}\right)$. Afterwards, the plates were rinsed with ultrapure $\mathrm{H}_{2} \mathrm{O}$ and dried in air (SR-LDH-MBT-HTMS were obtained).

\subsection{Examination Methods}

Phase composition and crystal structure of the samples were characterized using powder X-ray diffraction (XRD). XRD data were collected at room temperature using a PANalytical X'Pert MPD PRO diffractometer (Almelo, Holland) (Bragg-Brentano geometry, Ni-filtered $\mathrm{Cu} \mathrm{K} \alpha$ radiation, PIXcel ${ }^{1 \mathrm{D}}$ detector, step $0.02^{\circ}$ ). The exposition corresponded to about $2 \mathrm{~s}$ per step over the angular range of $4^{\circ}-90^{\circ}$. The range of the diffraction reflections 110 and $113\left(58^{\circ}-63^{\circ}\right)$ was studied with the exposition of $60 \mathrm{~s}$ per step.

The surface morphology of the samples was characterized by scanning electron microscopy equipped with an energy dispersive spectroscopy (SEM-EDS) from Hitachi (Tokyo, Japan) (model S-4100) operating at an acceleration voltage of $25 \mathrm{kV}$.

Atomic Force Microscopy (AFM) was used to measure samples roughness. Measurements were collected in a Multimode atomic force microscope (Nanoscope IV from Veeco, Plainview, NY, USA). Images were acquired in tapping mode, using silicon probes (nanowrold, Neuchâtel, Switzerland) operating at a resonance frequency of about $320 \mathrm{KHz}$ and a force constant of $42 \mathrm{~N} / \mathrm{m}$. Image analysis was performed using Gwiddeon software (version 2.37).

The hydrophobicity of the samples was evaluated by measuring the contact angle. Data were assessed employing an OCA-20 goniometer (DataPhysics Instruments, Filderstadt, Germany) equipped with a CCD camera and SCA20 software. Measurements were performed with a $2 \mathrm{~mL}$ droplet of water and recorded $5 \mathrm{sec}$ after the water drop deposition at room temperature. The contact angle Laplace-Young method was used to determine the contact angle.

X-ray photoelectron spectroscopy (XPS) (CEMUP - University of Porto, Porto, Portugal) was used to identify the expected characteristic elements on the surface of the SR-LDH films as well as their chemical state. XPS spectra were taken using a Kratos Axis Ultra HSA spectrometer (Manchester, UK). The excitation source was $\mathrm{Al} \mathrm{K} \alpha$ radiation running at $15 \mathrm{kV}$. The results were obtained through an analysis of the full spectra with peaks measured without patterning structure, and with the Shirley background subtraction.

Glow discharge optical emission spectrometry (GDOES) (Longjumeau, France) was used to perform chemical analysis and surface profiles of the films. GDOES depth profile analysis of the SR-LDH films was done using a HORIBA GD-Profiler 2 with a copper anode of $4 \mathrm{~mm}$ in diameter. Argon sputtering of the sample surface occurred at a pressure of $650 \mathrm{~Pa}$ and power of $30 \mathrm{~W}$.

The resistance to localized corrosion was investigated using the scanning vibrating electrode technique (SVET) (New Haven, CT, USA). These measurements were performed on samples with area of $1 \mathrm{~cm}^{2}$ glued to an epoxy support. A mixture of beeswax and colophony was used to insulate each sample leaving a window of a few $\mathrm{mm}^{2}$ exposed to the testing solution, $0.05 \mathrm{M} \mathrm{NaCl}$. The measurements 
were made with Applicable Electronics Inc. (Falmouth, MA, USA) instrument and the ASET software (version 2.0) from ScienceWares (USA). The vibrating microelectrode had a $10 \mu \mathrm{m}$ spherical platinum black tip and vibrated at $88 \mathrm{~Hz}$ with amplitude of $10 \mu \mathrm{m}$ at an average distance of $200 \mu \mathrm{m}$ from the surface of the sample. Each scan comprised $40 \times 40$ points.

\subsection{Antimicrobial Activity}

The antimicrobial activity of SR-LDH was tested on a recombinant bioluminescent strain of Escherichia coli [18] using light emission as a proxy for bacterial activity. Bacterial cell suspensions $\left(10^{7}\right.$ cell mL $\left.{ }^{-1}\right)$ were prepared in phosphate buffered saline $\left(8 \mathrm{~g} / \mathrm{L} \mathrm{NaCl}, 0.2 \mathrm{~g} / \mathrm{L} \mathrm{KCl}, 1.44 \mathrm{~g} / \mathrm{L} \mathrm{Na}_{2} \mathrm{HPO}_{4}\right.$, $0.24 \mathrm{~g} / \mathrm{L} \mathrm{KH}_{2} \mathrm{PO}_{4}, \mathrm{pH} 7.4$ ) from fresh liquid cultures. Then, $30 \mathrm{~mL}$ aliquots were transferred to sterile flasks and in each flask received one plate that was immersed in the cell suspension. Each experimental condition was tested in triplicate and two control-conditions were included. Biological controls consisting only of the cell suspension without any type of plate and negative controls exposed to AA2024 plates without the SR-LDH coating were included. All flasks were incubated at $25^{\circ} \mathrm{C}$ during a maximum period of $180 \mathrm{~min}$ and sub-samples for determination of bioluminescence were collected every $30 \mathrm{~min}$. Light emission was read in triplicate in a luminometer (TD-20/20, Turner Designs) and inactivation was assessed, in real time, as the decrease in bacterial light emission. Two independent assays were conducted, and the results were averaged.

\section{Results and Discussion}

The XRD patterns depicted in Figure 1a indicate formation of $\mathrm{Zn}$-Al layered double hydroxide intercalated with nitrate $\left(\mathrm{LDH}-\mathrm{NO}_{3}\right)$ on the aluminum alloy surface. Along with the peaks characteristic of the diffraction reflections (003) and (006) of $\mathrm{LDH}-\mathrm{NO}_{3}$, the peaks that can be attributed to $\mathrm{LDH}$ intercalated with $\mathrm{CO}_{3}{ }^{2-}$ or $(\mathrm{OH})^{-}[6]$ are also observed (marked in grey). Upon intercalation of MBT, the $\mathrm{LDH}-\mathrm{NO}_{3}$ phase disappears, while the $\mathrm{LDH}-\mathrm{CO}_{3} / \mathrm{LDH}-\mathrm{OH}$ phase did not suffer from significant changes. Therefore, a nitrate-to-MBT anion exchange is suggested. The broad peak corresponding to the average basal spacing $(d)$ value of about $0.99 \mathrm{~nm}$ can be attributed to the diffraction reflection (003) of the LDH phase formed as a result of the intercalation (see Figure 1a). This $d$-value is lower than that reported for bulk Zn-Al-MBT LDH (cf.: $1.678 \mathrm{~nm}$ ) [19] and may indicate that the aforementioned anion exchange is incomplete. It should be noticed that when difference in the effective size of the parent and the substituting anions is rather high, the anion exchange is accompanied by fragmentation of the LDH crystallites. This effect was found in LDH powders previously [20]. In the case of LDH structures directly grown on the metal surface, the crystallites are not free and the fragmentation effect is expected to be stronger. That is why the amount of the LDH phase after the MBT intercalation is certainly smaller than the amount of the parent $\mathrm{LDH}-\mathrm{NO}_{3}$ phase (see the higher-angle inset in Figure 1a). Besides, the fact that the crystallites are attached to the surface makes it difficult to complete the anion exchange. As a result, the LDH material with a set of different basal spacing is obtained. The morphology of the AA2024 substrate after growth of LDHs is shown in Figure 1b. The surface is covered with clusters of LDHs spatially resolved at the micrometer scale, consisting of vertically-aligned and merged nanoplates. In spite of similar microstructure, it is clear that MBT- has reacted with the grown layer because the $\mathrm{S}$ signal is detected in the EDS spectrum, Figure 1c. Moreover, the subsequent functionalization of the interface with hexadecyltrimetoxysilane (HTMS) was found to induce no additional changes to the grown surface structure. 
a

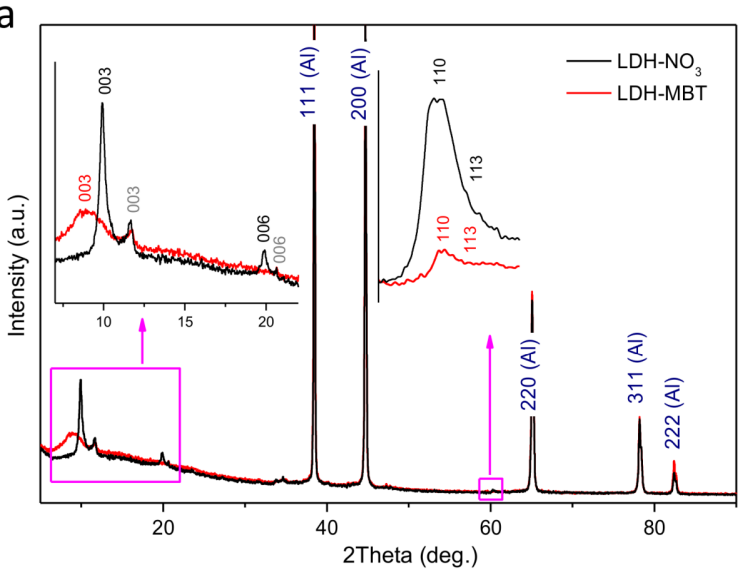

C

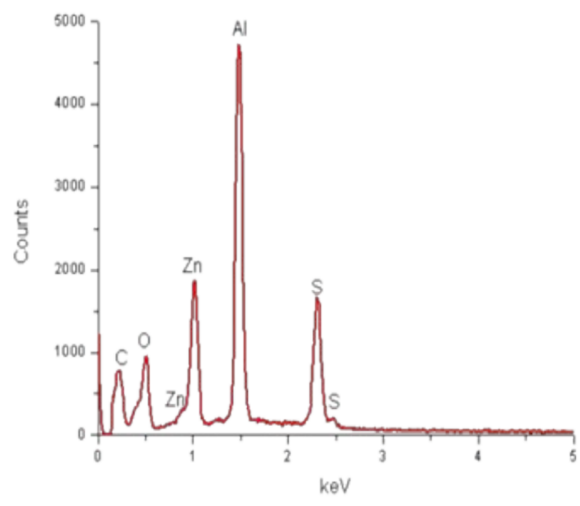

b
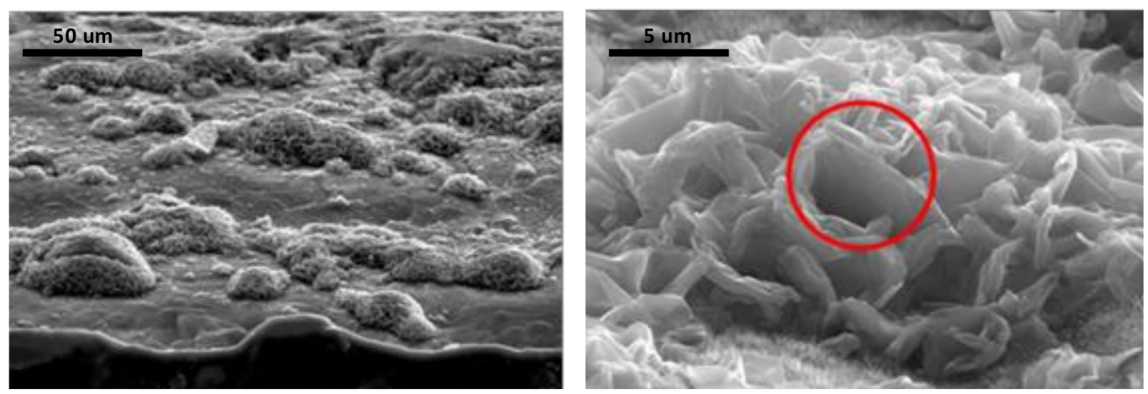

Figure 1. (a) X-ray diffraction (XRD) patterns obtained for spatially-resolved layered double hydroxide (SR-LDH) films, intercalated with nitrates (black) and 2-mercaptobenzothiazole (MBT) (red); (b) cross-section (right) and top-view (left) scanning electron microscopy (SEM) images of AA2024-T3 substrates covered with SR-LDH-MBT; (c) energy dispersive spectroscopy (EDS) spectrum of the cluster highlighted in $b$.

Figure 2 shows the chemical composition at the interface, sampled by surface sensitive technique XPS (panels a and b). SR-LDH-MBT and SR-LDH-MBT-HTMS (See Supplementary Materials Figure S1) show signals of S and Si in the XPS spectra, respectively. These findings enclose two important outcomes. The first is that MBT is indeed present in the modified surface, not disappearing with functionalization of HTMS. The second means that the silane modification occurs near the interface, otherwise a thick layer would mask the signal of the underlying SR-LDH-MBT.

For MBT, the position of the N1s peak (Figure 2a) is observed at $E_{\mathrm{b}}=400.8 \mathrm{eV}$ with a small shoulder occurring at $E_{\mathrm{b}}=399.3 \mathrm{eV}$. While the high energy peak is attributed to the MBT molecule, the shoulder could be related with the presence of a small amount of NaMBT. In fact, the full XPS spectra of MBT (results not shown) present a small peak assigned to KLL Auger line of $\mathrm{Na}$, which does not appear in the full spectra of other measured samples. Results from literature show that N1s spectrum of MBT sodium salt presents one peak with a binding energy of approximately $399 \mathrm{eV}$ [21], thereby supporting this assumption. In the $\mathrm{S} 2 p$ spectrum, two sets of signals differing in charge are detected, corresponding to two doublets of $\mathrm{S} 2 p$ electrons ( $\mathrm{S} 2 p_{3 / 2}$ and $\mathrm{S} 2 p_{1 / 2}$ peaks separated by $1.2 \mathrm{eV}$ ) [22,23]. The binding energy $\left(E_{\mathrm{b}}\right)$ of the most intense peak (S 2p $p_{3 / 2}$ ) of doublets is $E_{\mathrm{b}}=164.6$ and $162.4 \mathrm{eV}$. This is consistent with the structure of MBT in Figure 2e, which presents two sulfur atoms, one of which is in the 5-member ring and is called endo-type (S1), and another of exo-type (S2), the former having less negative charge than the latter due to a greater negative charge built on the exo atom [24,25].

In SR-LDH-MBT, the N1s peak shifts to lower energies and is detected at $399.3 \mathrm{eV}(\Delta \mathrm{E}=1.5 \mathrm{eV})$, indicating both deprotonation of the nitrogen atom and its interaction with metal cations [24-26]. At the same time, the two doublets of $\mathrm{S} 2 p$ for MBT (164.6 eV (S1) and $162.4 \mathrm{eV}(\mathrm{S} 2))$ are slightly shifted towards lower energies after the reaction with SR-LDH $\left(E_{\mathrm{b}}=163.9 \mathrm{eV}\right.$ for S1 $(\Delta \mathrm{E}=0.7 \mathrm{eV})$ and $E_{\mathrm{b}}=162.1 \mathrm{eV}$ for S2 $(\Delta \mathrm{E}=0.3 \mathrm{eV})$. Several studies [22-25] have reported that the interaction of 
MBT with metal surfaces leads to a shift of the two doublets of $S 2 p$ for higher energies. In our case the results obtained, namely the change in the N1s and a minor change in the S2p spectra suggest that the MBT is adsorbed to the surface of the SR-LDH films, and the N atom is most likely the one involved in the MBT/SR-LDH film connection. This can be due to the fact that intercalation of MBT is performed under a basic $\mathrm{pH}$ (aprox. 10), where MBT assumes the anionic form. In this form, the negative charge will be located between the nitrogen and the exo sulfur, which is the part of the molecule that interacts with the surface of LDH [27]. After reaction with HTMS, the XPS spectrum of the SR-LDH film (See Supplementary Materials Figure S1) presents, apart from peaks associated with N1s $\left(E_{\mathrm{b}}=399.3 \mathrm{eV}\right)$ and S2p $\left(E_{\mathrm{b}}=163.8 \mathrm{eV}\right.$ for S1 and $E_{\mathrm{b}}=162.1 \mathrm{eV}$ for S2) electrons, Si2p electrons with an $E_{\mathrm{b}}=102.3 \mathrm{eV}$ corresponding to $\mathrm{Si}$ in silanes $[28,29]$, indicating that functionalization has occurred near the interface.

Contact angle measurements performed before modification with MBT show that SR-LDH-NO are hydrophilic and therefore not capable of avoiding ingress of water and other electrolyte species $\left(24^{\circ} \pm 3^{\circ}\right.$, Figure $\left.2 \mathrm{c}\right)$. After modification with MBT, contact angle measurements show an increase in the hydrophobicity, consistent with hydrophobic nature of MBT and partial adsorption in the external surface of the nanoplates $\left(97^{\circ} \pm 7^{\circ}\right)$. However, the highest increase in contact angle was observed after grafting of HTMS. The contact angle increased to $144^{\circ} \pm 3^{\circ}$, on the verge of superhydrophobicity. This is again due to the combination of the roughness of LDHs with hydrophobic nature of the silane.

Figure 2d shows AFM micrographs of SR-LDH-MBT before and after modification with MBT. The root mean square roughness parameter (RMS) obtained by AFM was determined to be $0.35 \mu \mathrm{m}$ for the SR-LDH-NO ${ }_{3}$ surface and $0.52 \mu \mathrm{m}$ after reaction with MBT (SR-LDH-MBT). Often, the roughness increases with increasing grain size (single crystal within a bulk/thin film form) [30]. Rough surfaces have more nucleation sites and therefore more grains (crystallites) will appear. In addition, the existence of small grains with different orientation of crystallographic axes or the collision and coalescence of grains (forming a continuous or discontinuous film) can also contribute to roughness increase [31]. In this work one explanation for roughness increase is the possibility of partial fragmentation of LDH crystallites after modification with MBT, which can lead to the exposure of internal features of the LDHs structure. This implies that more grains, possibly with different sizes, shapes and orientations, will be exposed and contribute to the higher roughness of the film surface. This hypothesis is supported by GDOES analysis in which a decrease in the external layer thickness was observed (see next section). 

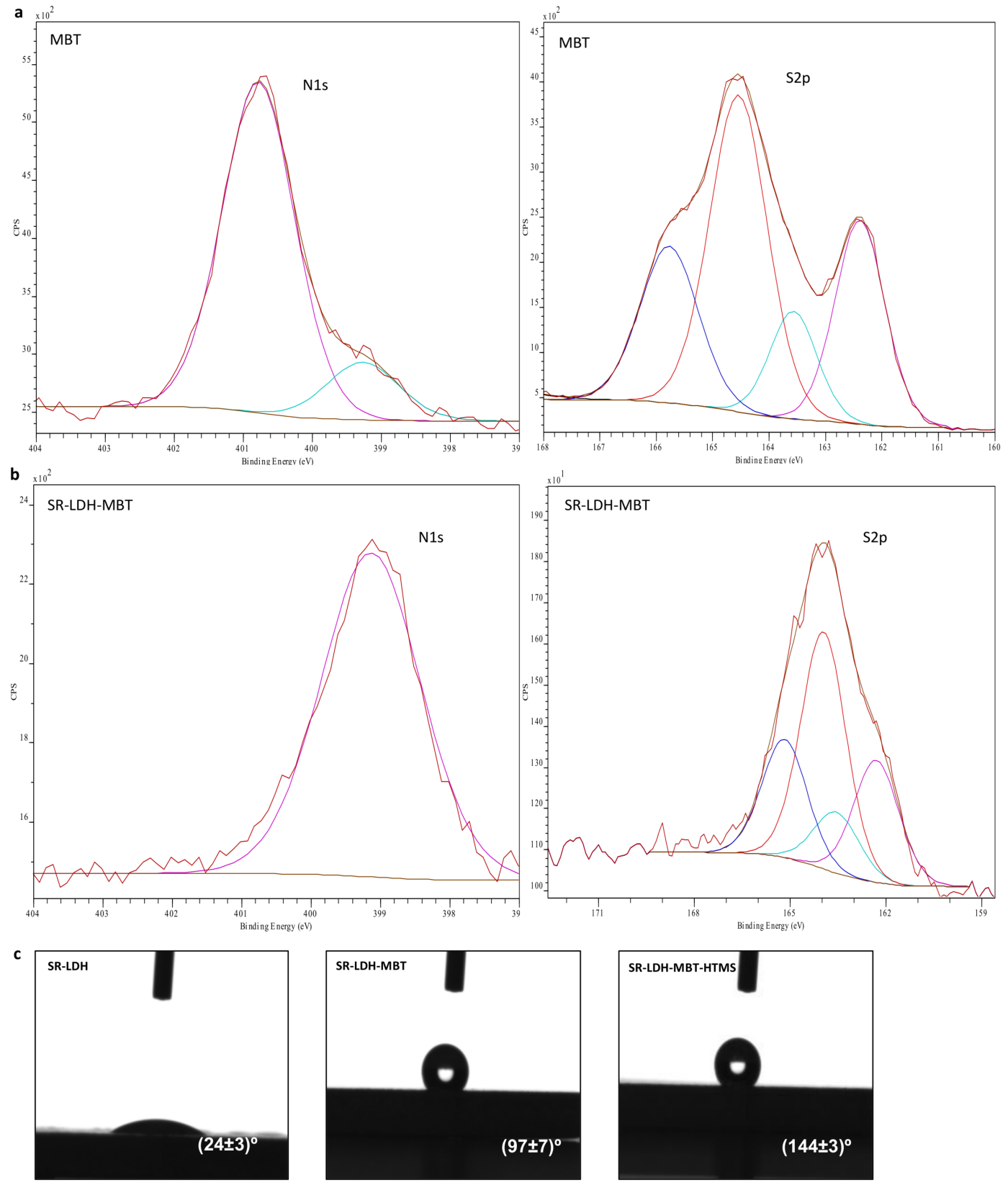

d
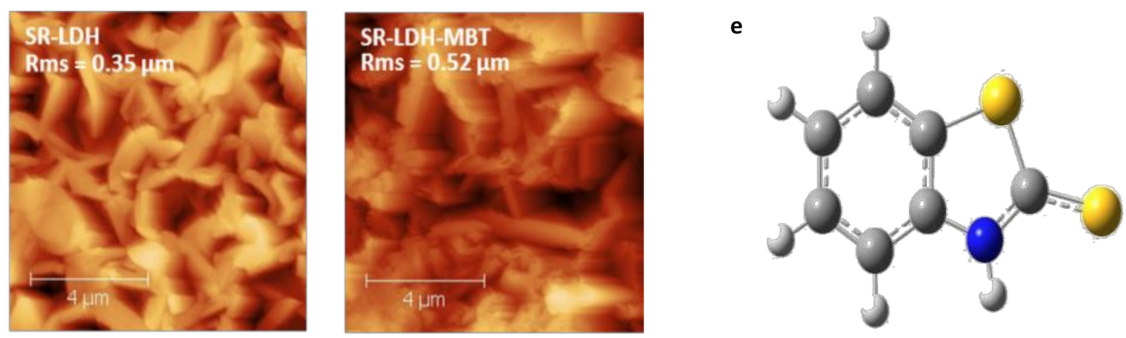

Figure 2. (a) and (b) X-ray photoelectron spectroscopy (XPS) spectra of MBT and SR-LDH-MBT; (c) contact angle measurements of SR-LDH films; (d) AFM topography images and roughness of SR-LDH and SR-LDH-MBT; (e) structure of MBT.

Glow discharge optical emission spectrometry (GDOES) was used to perform chemical analysis and surface elemental profiles on the SR-LDH films (Figure 3). Three main regions are found on 
AA2024 alloy samples after growth of LDHs using GDOES. Zone I corresponds to the LDH conversion layer, Zone II is ascribed to the aluminum oxide film and Zone III to the substrate.

In Figure 3a Zone I shows signals of $\mathrm{Zn}, \mathrm{O}, \mathrm{N}$ (some $\mathrm{Al}$ is detected as well), which is expected according to the chemical composition of the $\mathrm{Zn}-\mathrm{Al}$ SR-LDH-NO . In Zone II all the signals decrease except $\mathrm{Al}$, which increases. The strongest signals detected are $\mathrm{Al}$ and $\mathrm{O}$, consistent with the presence of aluminum oxide film. Then, in Zone III almost only Al can be detected (signal from $\mathrm{Cu}$ and Mg-containing intermetallics were not presented to facilitate the analysis of the spectra). Upon reaction with MBT, $\mathrm{S}$ is detected and N almost disappears, confirming the presence of MBT (Figure $3 b$ ). However, the external layer thickness is decreased, reaching Zone II within a shorter time when compared to the initial SR-LDH film, supporting the claim of fragmentation of the LDH crystallites that forms the film. On the other hand, the functionalization of the surface with HTMS had no effect on the composition of SR-LDH-MBT and thickness of the layer (Figure 3c). The main difference in the SR-LDH-MBT-HTMS sample is the presence of Si signal in Zone I. From the inset of Figure 3c, a 'spike' in Si profile is observed, which is consistent with HTMS being closer to the interface with air.

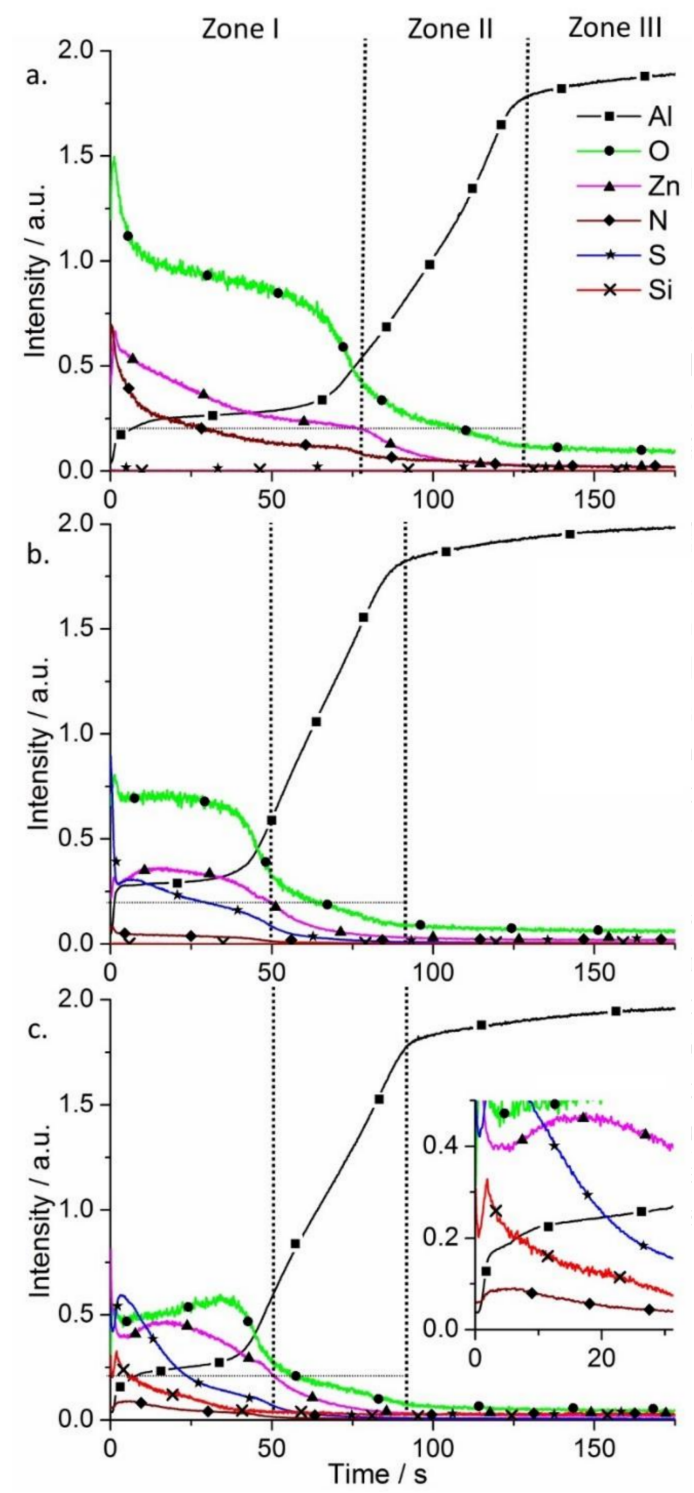

Figure 3. Qualitative glow discharge optical emission spectrometry (GDOES) depth profiles of AA2024 alloy plates after growth of SR-LDH films (a) SR-LDH-NO ; (b) SR-LDH-MBT and (c) SR-LDH-MBT-HTMS. 
From the results presented so far it is possible to confirm that a SR-LDH layer consisting of clusters of nanoplates vertically-oriented was grown on the surface of AA2024 (Scheme 1). Furthermore, the modification with deprotonated 2-mercaptobenzothiazole (MBT) in a post synthesis step of anion exchange and the subsequent grafting of hexadecyltrimetoxisilane (HTMS) were found to be successful.

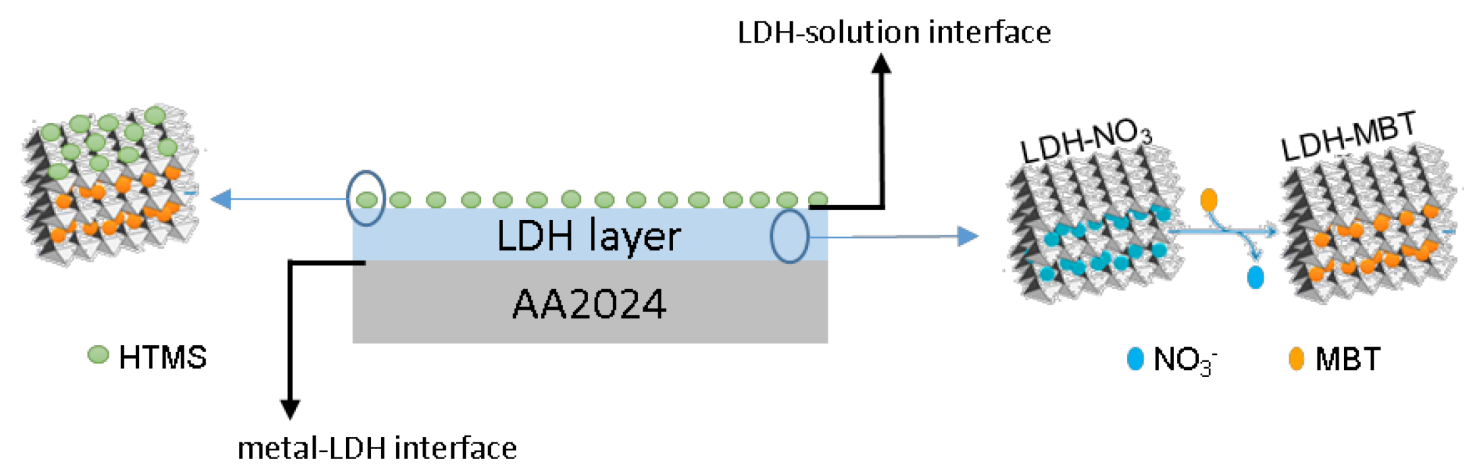

Scheme 1. Representation of SR-LDH nanostructured layer with intercalated corrosion inhibitor and surface modified on AA2024 substrate.

The corrosion resistance conferred by the LDH films was analyzed by SVET. This technique detects the ionic fluxes in solution related to the corrosion activity taking place at the metal surface. It gives information about the distribution of local anodes and cathodes, and their respective currents densities. Figure 4 presents SVET maps measured after 7 days of immersion in $0.05 \mathrm{M} \mathrm{NaCl}$. Positive current densities (in red) are associated with anodic reactions and the generation of $\mathrm{Al}^{3+}$, while negative currents (in blue) are due to the cathodic process of $\mathrm{O}_{2}$ reduction, according to the general reactions:

$$
\begin{aligned}
& \mathrm{Al}(s) \rightarrow \mathrm{Al}^{3+}(a q)+3 \mathrm{e} \\
& \mathrm{O}_{2}(a q)+2 \mathrm{H}_{2} \mathrm{O}+4 \mathrm{e} \rightarrow 4 \mathrm{OH}^{-}(a q)
\end{aligned}
$$

The SVET maps show that AA2024 is active in $\mathrm{NaCl}$ solution, with localized anodic activity counterbalanced by well spread cathodic activity. This is typical of pitting corrosion promoted by the presence of intermetallic sites in neutral saline conditions. The corrosion decreases when the surface is covered by LDH films. SR-LDH-NO 3 shows a clear improvement with respect to bare AA2024. The $\mathrm{LDH}-\mathrm{NO}_{3}$ film works as barrier between the metal substrate and the environment, hampering the transport of $\mathrm{O}_{2}$ and aggressive species to the reacting surface, and decreasing the area of metal available for reaction. The $\mathrm{LDH}$ can also capture chloride ions [32]. The best results were obtained with SR-LDH-MBT and SR-LDH-MBT-HTMS systems with MBT as the corrosion inhibitor. These films hold the properties of SR-LDH- $\mathrm{NO}_{3}$ but the addition of the inhibitor considerably improves the corrosion resistance of the substrate, as revealed by the SVET maps without currents above the noise level and no evidences of pitting or corrosion products after 7 days of immersion. The results confirm the effectiveness of LDH conversion films in improving corrosion resistance, especially when corrosion inhibitors are included. 
AA2024
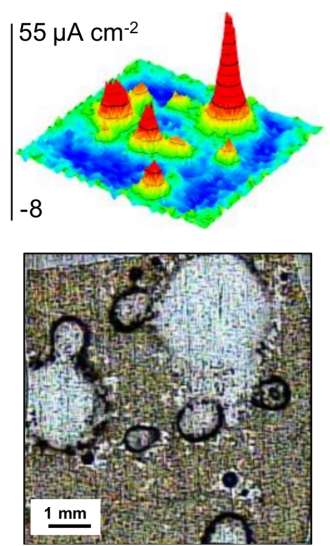

SR-LDH-NO ${ }_{3}$
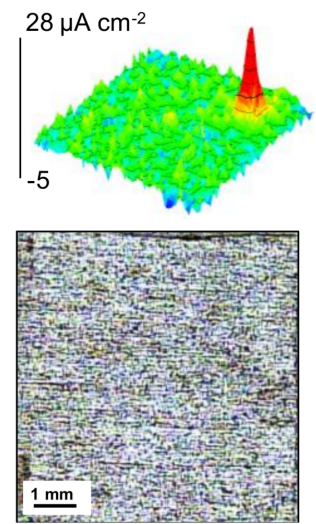

SR-LDH-MBT
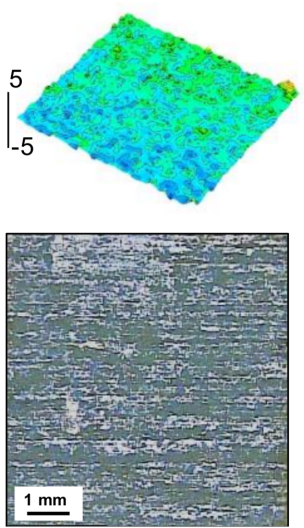

SR-LDH-MBT-HTMS
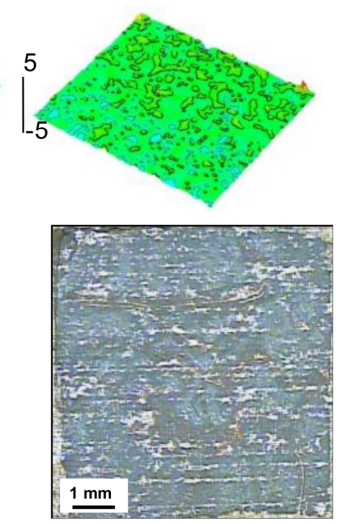

Figure 4. Scanning vibrating electrode technique (SVET) maps and photographs of samples surfaces after 7 days of immersion in $0.05 \mathrm{M} \mathrm{NaCl}$ of the bare alloy (AA2024), and the alloy with SR-LDH-NO SR-LDH-MBT and SR-LDH-MBT-HTMS.

The same substrates were tested for biological activity (Figure 5) using bioluminescence as an indicator of metabolic activity. The steepest decrease in light emission, interpreted as a stronger inhibitory effect on the model bacterium, corresponds to the SR-LDH-MBT treatment (Figure 5b) which can be explained by the profile of release of the biocide. UV-Visible spectrophotometry revealed that MBT, a biocide for which the minimum inhibitory concentration is $50 \mathrm{ppm}$, is more extensively released in solution without HTMS (SR-LDH-MBT). This may be associated with the displacing effect of HTMS, preventing wetting and release of MBT in solution and partial removal of excess of MBT located in the outer region of the film. In addition, it was possible to observe that the light emission associated with the activity of the bioluminescent bacteria decreased in a very similar way for SR-LDH-MBT and SR-LDH-MBT-HTMS, although the decrease was more significant for SR-LDH-MBT.
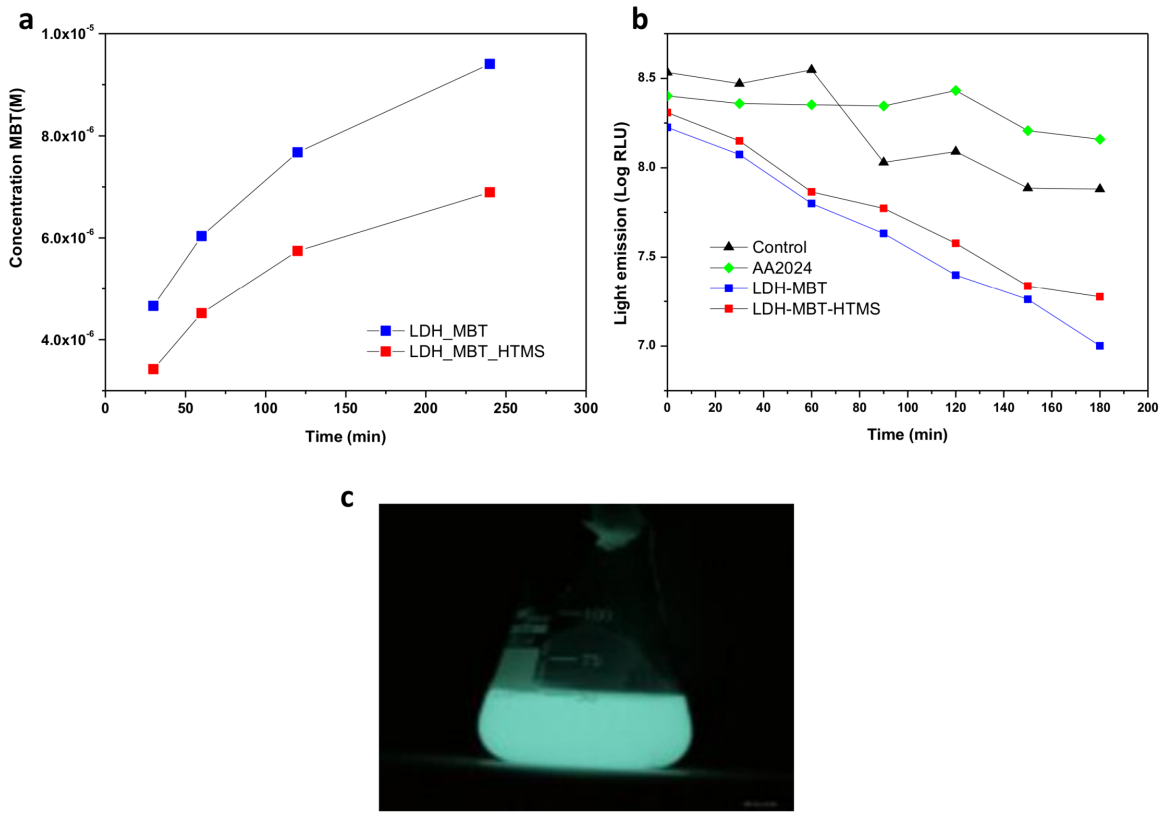

Figure 5. (a) Release profile of MBT; (b) antibacterial effect observed in the presence of SR-LDH films; (c) Escherichia coli bacterial light emission. 


\section{Conclusions}

SR-LDH conversion films were obtained on AA2024 substrates using a simple procedure consisting of immersion of the alloy in bath solution containing $\mathrm{Zn}^{2+}, \mathrm{NO}_{3}{ }^{-}$and $\mathrm{H}_{2} \mathrm{O}$. Under hydrothermal conditions the reaction with the substrate leads to the formation of $\mathrm{LDH}-\mathrm{NO}_{3}$ phases.

Upon reaction with MBT, SR-LDHs become less crystalline possibly due to a fragmentation of the LDH crystallites during the anion exchange. This claim is consistent with data obtained by GDOES, which demonstrate a decrease in SR-LDH thickness upon anion-exchange. The interfacial functionalization was achieved by grafting with the hydrophobic molecule HTMS. The grafting was verified by GDOES and led to an increase in the water contact angle, achieving almost a superhydrophobic character. XPS analysis confirmed the presence of MBT and HTMS in the SR-LDH modified layer, as well. Furthermore, XPS data suggest that MBT is most likely interacting with SR-LDH films via the $\mathrm{N}$ atom.

The SR-LDH films directly grown on AA2024 confer a remarkable corrosion resistance when compared to the bare substrate, even in the absence of corrosion inhibitor. However, the best results were found for SR-LDH-MBT and SR-LDH-MBT-HTMS. Furthermore, the biocidal effect observed in the presence of LDH films, in comparison to the biological and negative controls, is consistent with the release of MBT species as verified by a biological assay based upon bioluminescent bacteria.

Overall, these findings underline the potential of these surface treatments for anti-corrosion and anti-biofilm applications, since it combines both corrosion inhibition and biocidal action (MBT) with low surface energy, relevant to avoiding adhesion of bacteria and biofilm growth in processes such as fouling and biocorrosion.

Supplementary Materials: The following are available online at http://www.mdpi.com/2079-6412/9/5/328/s1, Figure S1. XPS spectra of SR-LDH-MBT after functionalization with HTMS.

Author Contributions: Formal analysis, C.S.N.; A.C.B.; A.N.S.; M.L.Z.; A.C.; A.A. and J.T.; Investigation, C.S.N.; Methodology, C.S.N.; A.C.B.; A.N.S.; M.S. and D.R.; Supervision, A.C. and J.T.; Writing original draft, J.T.; Writing, review \& editing, C.S.N.; M.L.Z., A.C.; A.A., J.T. and M.G.S.F.

Funding: This work was financed by Portugal 2020 through European Regional Development Fund (ERDF) in the frame of Operational Competitiveness and Internationalization Programme (POCI), in the scope of the project MAGICOAT POCI-01-0145-FEDER-016597 / PTDC/CTM-BIO/2170/2014 and in the scope of the project CICECOAveiro Institute of Materials, POCI-01-0145-FEDER-007679 (FCT Ref. UID/CTM/50011/2013), and co-financed by national funds through the FCT/MEC. This work in part was financed by the European project MULTISURF (Marie Skłodowska-Curie Research Program, grant agreement No 645676). JT thanks FCT for the research grant IF/00347/2013.

Conflicts of Interest: Authors declare no conflict of interest.

\section{References}

1. Müller, K.; Bugnicourt, E.; Latorre, M.; Jorda, M.; Sanz, Y.E.; Lagaron, J.M.; Miesbauer, O.; Bianchin, A.; Hankin, S.; Bölz, U.; et al. Review on the processing and properties of polymer nanocomposites and nanocoatings and their applications in the packaging. Nanomaterials 2017, 7, 74. [CrossRef]

2. Ferreira, M.G.S.; Zheludkevich, M.L.; Tedim, J.; Yasakau, K. Smart self-healing coatings for corrosion protection of aluminium alloys. In Handbook of Smart Coatings for Materials Protection; Makhlouf, A.S.H., Ed.; Elsivier: Cambridge, UK, 2013; pp. 224-267.

3. Shchukin, D.G.; Zheludkevich, M.; Yasakau, K.; Lamaka, S.; Ferreira, M.G.S.; Mohwald, H. Layer-by-layer assembled nanocontainers for self-healing corrosion protection. Adv. Mater. 2016, 18, 1672-1678. [CrossRef]

4. Twite, R.L.; Bierwagen, G.P. Review of alternatives to chromate for corrosion protection of aluminum aerospace alloys. Prog. Org. Coat. 1988, 33, 91-100. [CrossRef]

5. Collazo, A.; Hernandez, M.; Novoa, X.R.; Perez, C. Effect of the addition of thermally activated hydrotalcite on the protective features of sol-gel coatings applied on AA2024 aluminium alloys. Electrochim. Acta. 2011, 56, 7805-7814. [CrossRef] 
6. Tedim, J.; Zheludkevich, M.L.; Bastos, A.C.; Salak, A.N.; Lisenkov, A.D.; Ferreira, M.G.S. Influence of preparation conditions of Layered Double Hydroxide conversion films on corrosion protection. Electrochim. Acta 2014, 117, 164-171. [CrossRef]

7. Tedim, J.; Zheludkevich, M.L.; Bastos, A.C.; Salak, A.N.; Carneiro, J.; Maia, F.; Lisenkov, A.D.; Oliveira, A.B.; Ferreira, M.G.S. Effect of Surface Treatment on the Performance of LDH Conversion Films. ECS Electrochem. Lett. 2014, 3, C4-C8. [CrossRef]

8. Zhitova, E.S.; Krivovichev, S.V.; Pekov, I.V.; Yakovenchuk, V.N.; Pakhomovsky, Y.A. Correlation between the d-value and the M2+:M3+ cation ratio in Mg-Al-CO3 layered double hydroxides. Appl. Clay Sci. 2016, 130, 2-11. [CrossRef]

9. Uan, J.-Y.; Lin, J.-K.; Tung, Y.-S. Direct growth of oriented Mg-Al layered double hydroxide film on Mg alloy in aqueous $\mathrm{HCO}_{3}{ }^{-} / \mathrm{CO}_{3}{ }^{2-}$ solution. J. Mater. Chem. 2010, 20, 761-766. [CrossRef]

10. Chen, H.; Zhang, F.; Fu, S.; Duan, X. In Situ Microstructure Control of Oriented Layered Double Hydroxide Monolayer Films with Curved Hexagonal Crystals as Superhydrophobic Materials. Adv. Mater. 2006, 18, 3089-3093. [CrossRef]

11. Wang, F.; Guo, Z. Insitu growth of durable superhydrophobic Mg-Al layered double hydroxides nanoplatelets on aluminum alloys for corrosion resistance. J. Alloys Compd. 2018, 767, 382-391. [CrossRef]

12. Zhang, H.; Yin, L.; Liu, X.; Weng, R.; Wang, Y.; Wu, Z. Wetting behavior and drag reduction of superhydrophobic layered double hydroxides films on aluminum. Appl. Surf. Sci. 2016, 380, 178-184. [CrossRef]

13. Zhang, F.; Zhao, L.; Chen, H.; Xu, S.; Evans, D.G.; Duan, X. Corrosion resistance of superhydrophobic layered double hydroxide films on aluminium. Angew. Chem. Int. 2008, 47, 2466-2569. [CrossRef]

14. Kuznetsov, B.; Serdechnova, M.; Tedim, J.; Starykevich, M.; Kallip, S.; Oliveira, M.P.; Hack, T.; Nixon, S.; Ferreira, M.G.S.; Zheludkevich, M.L. Sealing of tartaric sulfuric (TSA) anodized AA2024 with nanostructured LDH layers. RSC Adv. 2016, 6, 13942-13952. [CrossRef]

15. Mata, D.; Serdechnova, M.; Mohedano, M.; Mendis, C.L.; Lamaka, S.V.; Tedim, J.; Hack, T.; Nixon, S.; Zheludkevich, M.L. Hierarchically organized Li-Al-LDH nano-flakes: A low-temperature approach to seal porous anodic oxide on aluminum alloys. RSC Adv. 2017, 7, 35357-35367. [CrossRef]

16. Wu, L.; Yang, D.; Zhang, G.; Zhang, Z.; Zhang, S.; Tang, A.; Pan, F. Fabrication and characterization of Mg-M layered double hydroxide films on anodized magnesium alloy AZ31. Appl. Surf. Sci. 2018, 431, 177-186. [CrossRef]

17. Tedim, J.; Zheludkevich, L.; Salak, A.N.; Ferreira, G.S. Nanostructured LDH-container layer with active protection functionality. J. Mater. Chem. 2011, 39, 15464-15470. [CrossRef]

18. Alves, E.; Carvalho, C.M.; Tome, J.P.; Faustino, M.A.; Neves, M.G.; Tome, A.C.; Cavaleiro, J.A.; Cunha, A.; Mendo, S.; Almeida, A. Photodynamic inactivation of recombinant bioluminescent Escherichia coli by cationic porphyrins under artificial and solar irradiation. J. Ind. Microbiol. Biotechnol. 2008, 35, 1447-1454. [CrossRef]

19. Serdechnova, M.; Salak, A.N.; Barbosa, F.S.; Vieira, D.E.L.; Tedim, J.; Zheludkevich, M.L.; Ferreira, M.G.S. Interlayer intercalation and arrangement of 2-mercaptobenzothiazolate and 1,2,3-benzotriazolate anions in layered double hydroxides: In situ X-ray diffraction study. J. Solid State Electrochem. 2016, 233, 158-165. [CrossRef]

20. Salak, A.N.; Tedim, J.; Kuznetsova, A.I.; Zheludkevich, M.L.; Ferreira, M.G.S. Anion exchange in Zn-Al layered double hydroxides: In situ X-ray diffraction study. Chem. Phys. Lett. 2010, 495, 73-76. [CrossRef]

21. Yoshida, T.; Yamasaki, K.; Sawada, S. X-Ray Photoelectron Spectroscopic Study of 2-Mercaptobenzothiazole Metal-Complexes. Bull. Chem. Soc. Jpn. 1979, 52, 2908-2912. [CrossRef]

22. Finsgar, M.; Merl, D.K. An electrochemical, long-term immersion, and XPS study of 2-mercaptobenzothiazole as a copper corrosion inhibitor in chloride solution. Corros. Sci. 2014, 83, 164-175. [CrossRef]

23. Finsgar, M.; Merl, D.K. 2-Mercaptobenzoxazole as a copper corrosion inhibitor in chloride solution: Electrochemistry, 3D-profilometry, and XPS surface analysis. Corros. Sci. 2014, 80, 82-95. [CrossRef]

24. Kazansky, L.P.; Pronin, Y.E.; Arkhipushkin, I.A. XPS study of adsorption of 2-mercaptobenzothiazole on a brass surface. Corros. Sci. 2014, 89, 21-29. [CrossRef]

25. Arkhipushkin, I.A.; Pronin, Y.E.; Vesely, S.S.; Kazansky, L.P. Electrochemical and XPS study of 2-mercaptobenzothiazole nanolayers on zinc and copper surface. Int. J. Corros. Scale Inhib. 2014, 3, 78-88. [CrossRef] 
26. Zerulla, D.; Uhlig, I.; Szargan, R.; Chasse, T. Competing interaction of different thiol species on gold surfaces. Surf. Sci. 1998, 402, 604-608. [CrossRef]

27. Galvao, T.L.P.; Kuznetsova, A.; Gomes, J.R.B.; Zheludkevich, M.L.; Tedim, J.; Ferreira, M.G.S. A computational UV-Vis spectroscopic study of the chemical speciation of 2-mercaptobenzothiazole corrosion inhibitor in aqueous solution. Theor. Chem. Acc. 2016, 135, 78-89. [CrossRef]

28. Logofatu, C.; Negrila, C.C.; Ghita, R.V.; Ungureanu, F.; Cotirlan, C.; Manea, C.G.A.; Lazarescu, M.F. Study of $\mathrm{SiO} / \mathrm{Si}$ interface by surface techniques. In Crystalline Silicon - Properties and Uses; Basu, S., Ed.; InTech: Rijeka, Croatia, 2011; pp. 25-42.

29. Moulder, J.F.; Stickle, W.F.; Sobol, P.E.; Bomben, K.D. Handbook of X-ray Photoelectron Spectroscopy; Perkin-Elmer Corp: Eden Prairie, MN, USA, 1992.

30. Becker, R. Effects of strain localization on surface roughening during sheet forming. Acta Mater. 1998, 46, 1385-1401. [CrossRef]

31. Freund, L.B.; Suresh, S.S. Thin Film Materials: Stress, Defect Formation and Surface Evolution; Cambridge University Press: Cambridge, UK, 2003.

32. Tedim, J.; Kuznetsova, A.; Salak, A.N.; Montemor, F.; Snihirova, D.; Pilz, M.; Zheludkevich, M.L.; Ferreira, M.G.S. Zn-Al layered double hydroxides as chloride nanotraps in active protective coatings. Corros. Sci. 2012, 55, 1-4. [CrossRef]

(C) 2019 by the authors. Licensee MDPI, Basel, Switzerland. This article is an open access article distributed under the terms and conditions of the Creative Commons Attribution (CC BY) license (http://creativecommons.org/licenses/by/4.0/). 